УДК 550.831

\title{
ЗАВИСИМОСТЬ НЕПРИЛИВНЫХ ВАРИАЦИЙ СИЛЫ ТЯЖЕСТИ ОТ ТЕМПЕРАТУРНОГО РЕЖИМА ПОГРАНИЧНОГО СЛОЯ АТМОСФЕРЫ
}

\author{
Ю. В. Антонов \\ Воронежский государственный университет \\ Поступила в редакцию 20 ноября 2019 г.
}

\begin{abstract}
Аннотация: анализ неприливных аномалий силь тяжести показал, что наблюдается корреляционная связь между измерениями силы тяжести и наружной температурой воздуха. Поскольку измерительная система изолирована с помощью термостатирования, то естественно причиной изменения силь тяжести можно связать с температурными колебаниями атмосферы, которые по большей части своей определяются метеоусловиями. Элементарные расчеть показывают, что вариации могут достигать амлитуды $\pm 0,1$ мГал. Стационарные наблюдения силь тяжести во Владимире, Арти (Екатеринбург) и Бишкеке (Киргизия) подтверждают этот вывод.

Ключевье слова: лунно-солнечные вариации силь тяжести; неприливнье вариачии силь тяжести; температура воздуха; плотность воздуха
\end{abstract}

\section{DEPENDENCE OF NON-TIDAL VARIATIONS OF GRAVITY ON THE TEM- PERATURE REGIME OF THE BOUNDARY LAYER OF THE ATMOSPHERE}

\author{
Yu. V. Antonov \\ Voronezh State University \\ Received 20 November 2019
}

\begin{abstract}
: analysis of non-tidal gravity anomalies showed that there is a correlation between gravity measurements and outdoor air temperature. Since the measuring system is isolated by means of thermostating, the natural cause of the change in gravity can be attributed to the temperature fluctuations of the atmosphere, which for the most part are determined by weather conditions. Elementary calculations show that the variations can reach an amplitude of $=0.1 \mathrm{mGal}$. Stationary observations of gravity in Vladimir, Arti (Yekaterinburg) and Bishkek (Kyrgyzstan) confirm this conclusion.

Keywords: lunar-solar gravity variations; non-tidal gravity variations; air temperature; air density
\end{abstract}

\section{Введение}

Как показывают исследования [1-6], неприливные вариации силы тяжести во времени определяются лунно-солнечными вариациями, землетрясениями, ударами корональных выбросов масс по магнитосфере и метеорных потоками по атмосфере Земли и т. д. Год 2018 пришелся на год спокойного Солнца, когда воздействие космических факторов на неприливные вариации оказались минимальными. Поскольку влияние космических факторов невелико, то было решено проанализировать влияние метеорологических факторов на показания измерений гравиметра.

\section{Исходные данные}

При написании данной статьи использованы мониторинговые наблюдения силы тяжести, выполненные в лаборатории - обсерватории Института геофизики УрО РАН (ИГФ УрО РАН). (п. Арти, Екатеринбург), Бишкекском геодинамическом полигоне РАН (г. Бишкек, Киргизстан) и в Заполье Владимирской области (обсерватория ИФЗ РАН). Измерения силы тяжести на последних двух станциях выполнялись гравиметром CG - 5 AUTOGRAV. В Бишкеке станция расположена в 30 км за городом в штольне, так что технические помехи практически исключены. В Заполье обсерватория расположена недалеко от отеля и 
парка развлечений, что сказывается на качестве измерений. В Арти используется для наблюдений приливной гравиметр gPhone (Micro $-\mathrm{g}-$ LaCoste), a сама станция далеко от Екатеринбурга. Все приборы имеют программное обеспечение, которое позволяет вычислять теоретические значения силы тяжести от Луны и Солнца и исключать их из наблюденных значений. Оставшуюся часть измерений, условно назовем неприливной вариацией. Под неприливными вариациями силы тяжести будем понимать все изменения этих полей, исключая лунно-солнечные вариации силы тяжести, вне зависимости от источника их происхождения. Так что неприливная вариация может служить источником для изучения внутреннего строения Земли и космического пространства вокруг Земли.

\section{Методика обработки гравиметрических измерений}

Вычисление неприливных вариаций силы тяжести сейчас делается следующим образом. На первом этапе исключается притяжение Луны и Солнца. После этого по исправленным значениям определяется линейный тренд, который тоже исключается. Значения тренда в основном отражают в себе сползание нуль-пункта прибора и какую-то низкочастотную часть изменения внешнего гравитационного поля. Оставшуюся часть вариаций после исключения лунно-солнечной части и тренда назовем неприливной вариацией силы тяжести. Далее неприливная вариация с помощью метода осреднения, делится на локальную (остаточную) и осредненную неприливные вариации $[1,2]$. Кстати, локальная неприливная вариация может быть получена методом осреднения непосредственно по исходным наблюдениям, минуя операции учета лунносолнечных вариаций силы тяжести и смещения нульпункта прибора [2]. Это обстоятельство очень упрощает обработку. Локальная вариация силы тяжести, полученная по исходным наблюдениям, и локальная вариация, полученная обычным путем, практически совпадают между собой. Разность между ними не превышает одного микрогала, что минимум на два порядка меньше амплитуды наблюдаемых неприливных вариаций и погрешности измерений.

\section{Обсуждение неприливных вариаций силы тяжести}

За весь 2018 год была проведена соответствующая обработка наблюденных вариаций силы тяжести и получены неприливная, локальная и осредненная вариации силы тяжести. Рассмотрим это на практическом материале (рис. 1). Для примера взяты мониторинговые наблюдения на станции Арти (г. Екатеринбург) с апреля по декабрь 2018 г. На рис. 1а приведены наблюденные значения силы тяжести после исключения лунно-солнечных вариаций. Кривая силы тяжести за девятимесячный период изменяется всего лишь на 0,5 мГал и имеет линейный тренд изменения. Есть все основания полагать, что это изменение обуславливаются смещением нуль-пункта и изменением температуры внутри прибора (рис. 1б, кривая 2). Температура в приборе за это время изменилась всего лишь на 0,016 градуса по Цельсию. На линейном фоне вариации силы тяжести имеются локальные отклонения до 0,05 мГал, которые коррелируют с изменением температуры в помещении, где располагается гравиметр (рис. 1б, кривая 1). Температура в помещении естественно определяется температурой на улице. Тем более что в это время на улице было лето, и помещение не отапливалось.

Обратим внимание на наиболее выраженный минимум вариации силы тяжести (рис. 1a), который представлен в более крупном масштабе на рис. 2а. Минимум приурочен к концу мая и июню месяцу (со 140 по 175 день). Практически к тем же дням приурочен температурный минимум (рис. 2б), исключая двухдневное потепление 6-7 июня (156-157 дни). По крайней мере, на первый взгляд имеется полная зависимость изменение силы тяжести от изменения от температуры атмосферы.

Наблюдается ли подобная зависимость в других пунктах Евразийского континента? Рассмотрим взаимосвязь неприливных вариаций с изменением температуры в г. Владимире. На (рис. $3 a$ ) приведены среднесуточный ход (кривая 2) и текущее изменение температуры (кривая 1) с дискретностью 3 часа. Среднесуточный ход температуры практически полностью повторяет изменение неприливной вариации силы тяжести. А вот текущие изменения температуры и неприливной вариации несколько сдвинуты относительно друг друга: на рис. 3в, г они приведены специально в увеличенном масштабе. Вероятной причиной может служить то, что температура измеряется на высоте 2 м, а неприливная вариация определяется пограничным слоем (2-3 км). А вообще-то данный вопрос требует дополнительных исследований. Для станции во Владимире приведем также дополнительно графики сравнения температуры и давления: в целом давление и температура находятся в противофазе (рис. 4a, б).

Ничем не отличается зависимость показаний гравиметра от температуры в г. Бишкек (рис. 5а, б), хотя высота расположения станции в отличие от равнинных станций Арти и Владимир составляет чуть более 1600 м. Кроме того в Бишкеке приведены расчетные значения лунно-солнечных вариаций силы тяжести (рис. 5в), где максимум новолуния (14 октября) строго совпадает с днем понижения температуры воздуха, но, как показал дальнейший анализ, это совпадение не всегда бывает. Тем не менее, фазы луны и характер вариаций и погода связаны между собой, и в этом нет ничего удивительного

Таким образом, приведенные примеры указывают на уверенную корреляцию между изменениями температуры атмосферы и неприливных вариаций силы тяжести. Можно это объяснить изменением плотности атмосферы. С понижением температуры повышается плотность атмосферы (таблица). Атмосфера находится выше пункта наблюдения, поэтому значения силы тяжести уменьшаются. Для грубой оценки значения силы тяжести можно воспользоваться притяжением 

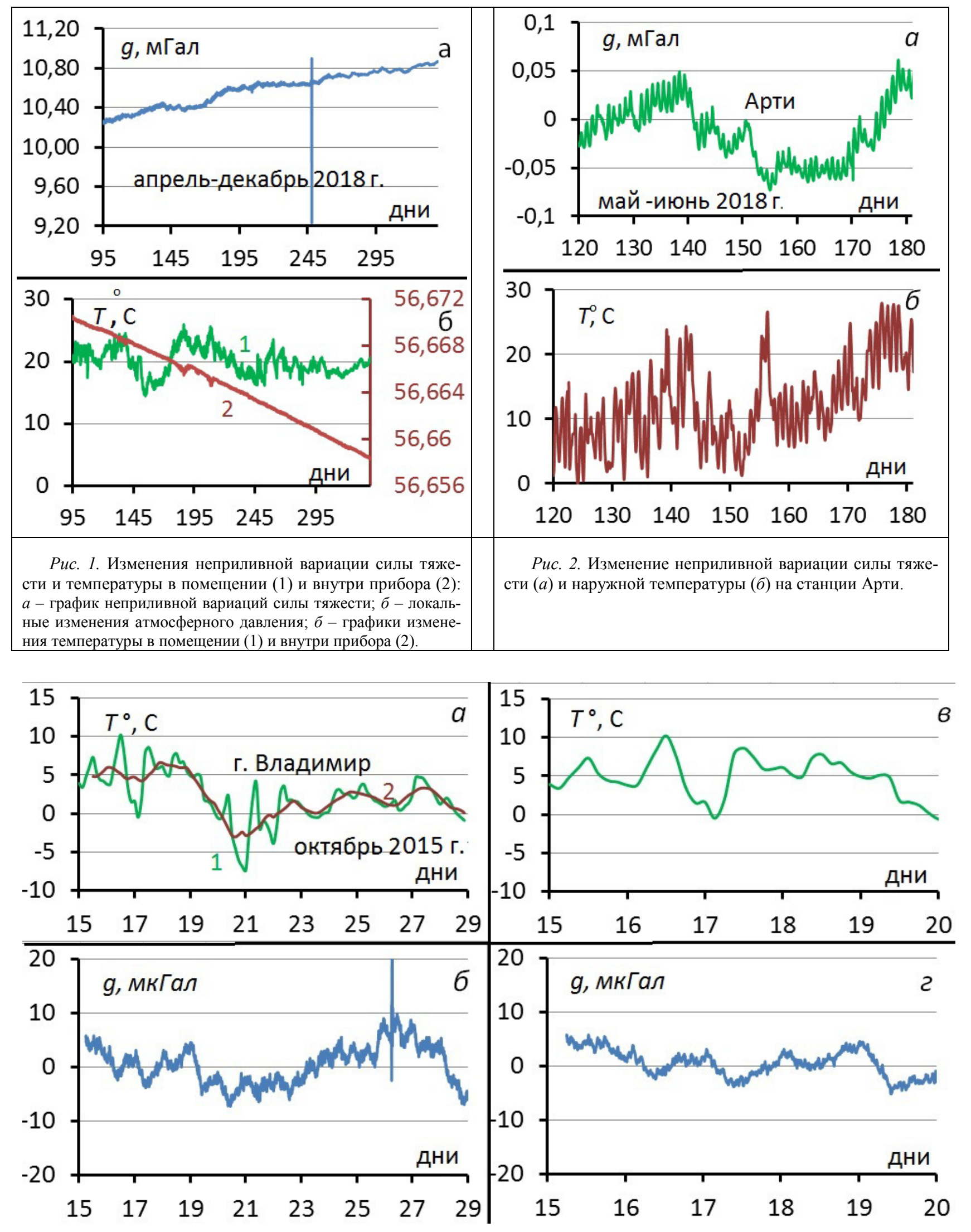

Puc. 3. Изменение наружной температуры $(a, b)$ и неприливной вариации силы тяжести $(\sigma, 2): 1-$ изменение наружной температуры с шагом дискретизации 3ч; 2 - осреднённые значения наружной температуры на интервале одни сутки. 


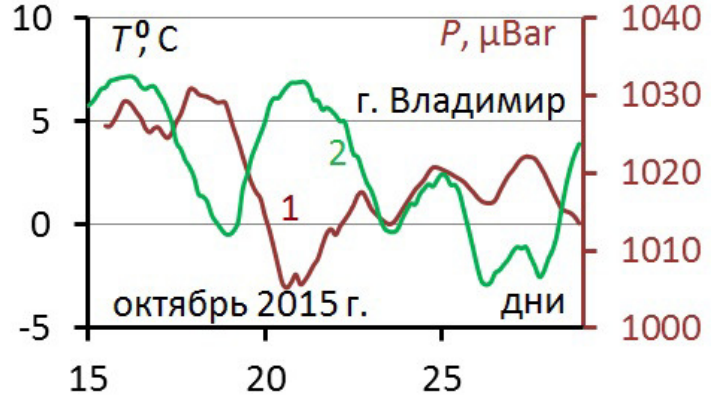

Puc. 4. Сравнение графиков наружной температуры и давления атмосферы.
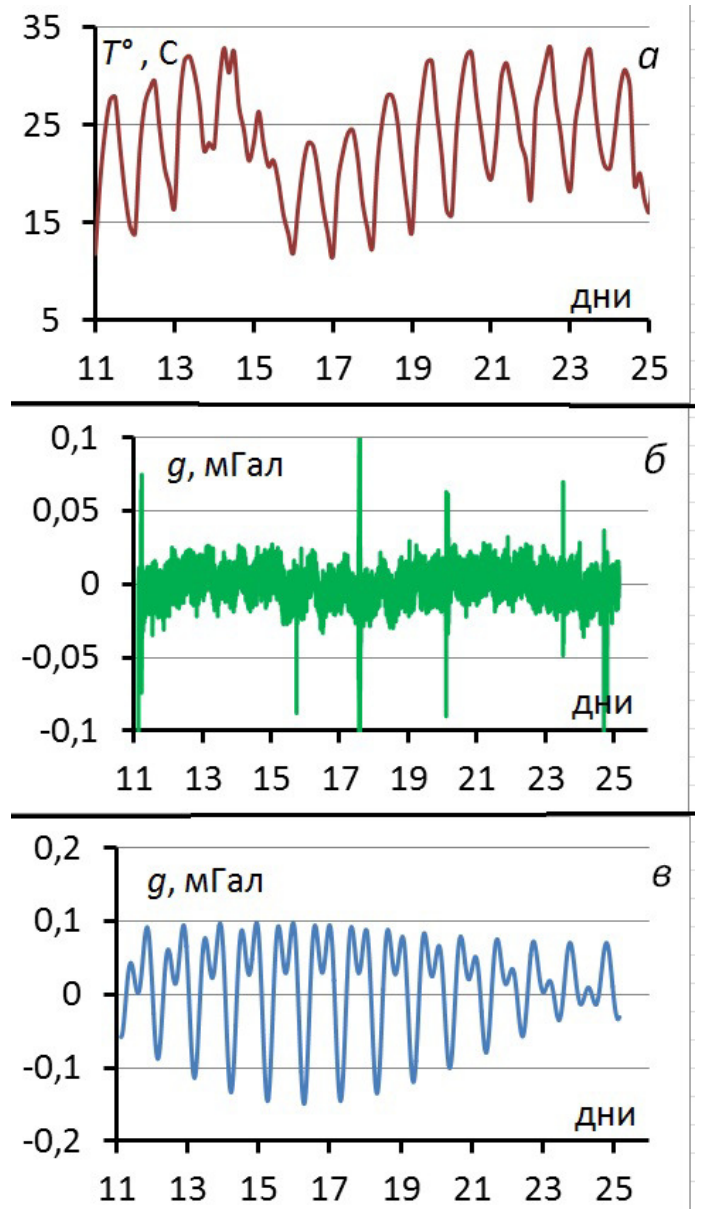

Puc. 5. Сравнение графиков наружной температуры (a), неприливной вариации (б) и лунно-солнечных вариации силы тяжести (в) в Бишкеке.

Зависимость плотности

Таблица

атмосферного воздуха от температуры

\begin{tabular}{|c|c|c|c|}
\hline $\mathrm{T}, \mathrm{C}$ & $\kappa \Gamma / \mathrm{M}^{3}$ & $\mathrm{~T}, \mathrm{C}$ & $\kappa \Gamma / \mathrm{M}^{3}$ \\
\hline 30 & 1,1644 & 0 & 1,292 \\
\hline 25 & 1,1839 & -5 & 1,3163 \\
\hline 20 & 1,2041 & -10 & 1,3413 \\
\hline 15 & 1,225 & -15 & 1,3673 \\
\hline 10 & 1,2466 & -20 & 1,3943 \\
\hline 5 & 1,269 & -25 & 1,4224 \\
\hline
\end{tabular}

плоскопараллельного слоя:

$$
\Delta \mathrm{g}=0,04196 \mathrm{H},
$$

где $\Delta \mathrm{g}$ - приращение силы тяжести; б - избыточная плотность; Н - мощность слоя.

Плотность воздуха при нуле градусов и стандартном давлении составляет $1,29310^{-3} \Gamma / \mathrm{cm}^{3}$ (таблица). Зависимость плотности атмосферы от температуры взята из [7]. Изменение плотности воздуха на 10 градусов приблизительно равно $(0,04-0,05) 10^{-3}$ г/ $\mathrm{cm}^{3}$ в зависимости от того, в каком диапазоне температур находимся. Тогда сила тяжести от пятикилометрового слоя атмосферы будет равна около 0,01 мГал. Учитывая, что в пограничном слое (около 2-3 км) находится $86 \%$ всей массы атмосферы [8], то указанная величина в 0,01 мГал несколько маловата по сравнению с приращениями силы тяжести на рис. 2, 3, 4. Если перепад температур взять 15 градусов, то сила притяжения увеличится всего лишь в полтора раза. Обычно перепад температур колеблется около величины 10 градусов.

Но ведь состояние атмосферы определяется не только температурой. Вносят свой вклад влажность, водность и давление [6-11]. Все это связано между собой Влажность, например, уменьшает плотность, а давление наоборот увеличивает плотность. Водность определяется в основном осадками. Можно попытаться воспользоваться величиной осадков (дождя или снега), которые всегда фиксируются метеостанциями. Допустим, что выпало осадков 50 мм. Это сильный дождь. Плотность воды известна. Если дождь выпал, вода упала ниже уровня гравиметра, то притяжение силы тяжести ничтожно (около одного двух микрогалов), Поэтому притяжение воды, просочившейся в грунт воды после весеннего половодья, тоже не так велико, не говоря об одноразовом ливне. Если говорить о плотности дождя во время его выпадения, то здесь четких критериев по оценке плотности атмосферы нет. Сумму выпавших осадков трудно использовать для вычисления плотности приземной атмосферы. Водность кучево-дождевых облаков [7, 10] варьирует в широких пределах, объем облаков меняется во времени и пространстве. В целом, наверное, водность дает не меньший эффект влияния, чем температура, но это вопрос требует отдельного исследования.

Отметим следующие особенности в поведении неприливной вариации силы тяжести и температурной кривой. Вернемся к рис. 5. Температура воздуха резко падает (10-15 градусов), а потом примерно неделю возвращается к исходному уровню. В то же время суточный ход температуры составляет 10-15 градусов, изменению температуры соответствуют тоже вариации силы тяжести, но по амплитуде в несколько раз меньше (рис. 3в, г) общей вариации силы от понижения температуры. Видимо, это объяснить можно с тем, что крупные понижения температуры связаны с мощными атмосферными фронтами, захватывающими очень высокие атмосферные слои. А прогрев воз- 
духа идет со стороны земной поверхности. Поэтому из-за плохой теплопроводности воздуха требуется продолжительное время для прогрева холодного воздуха, пришедшего с атмосферным фронтом. Кстати, данные о температуре на метеостанциях взяты из [12].

\section{Заключение}

Таким образом, по результатам можно уверенно сказать, что неприливные вариации силы тяжести определяются не только воздействием внешних космических сил и геодинамическими процессами, протекающими внутри Земли, но и атмосферой Земли (в конкретном случае ее температурой). Атмосфера окружает Землю, поэтому влияние всех внешних и внутренних факторов находит отклик в атмосфере, тем самым определяя состояние, как самой атмосферы, так и состояние геофизических полей внутри и вне её.

Автор благодарит Бебнева А. С. за предоставленный материал по ст. Арти.

\section{ЛИТЕРАТУРА}

1. Антонов, Ю. В. Пульсации неприливных вариаций силы тяжести / Ю. В. Антонов // Изв. ВУЗов. Геол. и разведка. 2014. - № 5. - С. 54-57.

2. Антонов, Ю. В. Разделение неприливных вариаций силы тяжести на основе спектрального анализа и метода осреднения/ Ю. В. Антонов Вестник Воронеж. гос. ун-та. Сер.: Геология. - 2016. - №2. - С. 100-106.

\section{ФГБОУ ВО Воронежский государственный университет}

Антонов Юрий Васильевич, доктор технических наук, профессор кафедры геофизики

E-mail:yuriyantonov@yandex.ru

Тел.: +7(473) 2208385
3. Антонов, Ю. В. Синхронные пульсации в неприливных вариациях гравитационного и сейсмического полей / Ю. В. Антонов, И. А. Сизаск // Геология и разведка. Изв. ВУЗ. 2015. - №5. - С. 46-52.

4. Антонов, Ю. В. Сравнение приливных вариаций силы тяжести и вертикальной составляющей сейсмографа / Ю. В. Антонов, И. Ю. Антонова // Геофизика. - 2013. - №2. - С. $27-31$.

5 Антонов, Ю. В. Влияние атмосферного фронта на показания гравиметров и сейсмометров / Ю. В. Антонов // Геология и разведка. Изв. ВУЗ. - 2017. - №4. - С. 66-71.

6. Антонов, Ю.В. Всплески неприливных вариаций силы тяжести / Ю. В. Антонов // Геофизика. - 2017. - №1. - С. $28-34$.

7. Матвеев, Л. Т. Физика атмосферы / Л. Т. Матвеев. - Л.: Гидрометеоиздат, 2000, $780 \mathrm{c.}$

8. Boy, J.-P. Global atmospheric loading and gravity / J.-P. Boy, J. Hinderer, P. Gegout // Phys. Earth Planet. Inter. - 1998. - V. 109. - P. 161-177.

9. Бычков, С. Г. Вычисление аномалий силы тяжести при высокоточных гравиметрических съемках / С. Г. Бычков, А. С. Долгаль, А. А. Симанов. - Пермь, УрО РАН, 2015, - 142 с.

10. Калинин, Н. А. Методика расчета водности и водозапаса кучево- дождевой облачности/ Н. А. Калинин, А. А.Смирнова // Вестник Удмуртского ун-та. Биология, науки о Земле. - Вып. 1. - 2008. - С. 59-72.

11. Howard, T. A. Stealth Coronal Mass Ejections: A Perspective / T. A. Howard, R. A. Harrison // Solar Physics. - 2013. C. doi: 10.1007/s11207-012-0217-0.

12. Архив погоды [Электронный ресурс] - Режим доступа: rp5.ru (дата обращения 20.11.2019).

\section{Voronezh State University}

Antonov Yu. V., Doctor of Engineering Sciences, professor of

Geophysical Department

E-mail:yuriyantonov@yandex.ru

Tel.:+7 (473) 2208385 